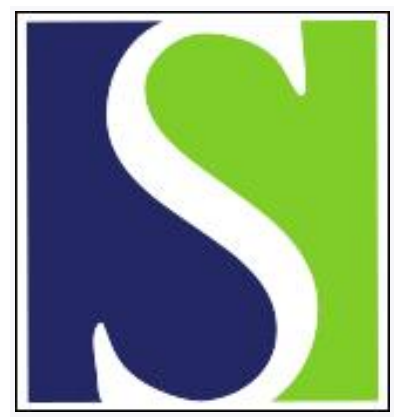

Scand J Work Environ Health 2020;46(2):188-197

https://doi.org/10.5271/sjweh.3850

Published online: 27 Aug 2019, Issue date: 01 Mar 2020

Does occupational lifting affect the risk of hypertension? Cross-sectional and prospective associations in the Copenhagen City Heart Study

by Korshøj M, Hannerz H, Marott JL, Schnohr P, Prescott E, Clays E, Holtermann A

Heavy lifting acutely increases blood pressure. However, only few inconclusive studies have investigated the prospective relation between heavy occupational lifting and hypertension. Our exploratory prospective analyses suggest that workers using anti-hypertensives or aged 50 years or older may be vulnerable to increases in blood pressure from heavy occupational lifting. However, further research is needed to confirm these associations.

Affiliation: National Research Centre for the Working Environment, Lersø Parkallé 105, 2100 Copenhagen. mkl@nfa.dk

Refers to the following texts of the Journal: 2005;31(6):409-437 2007;33(6):405-424 1989;15(3):165-179

Key terms: blood pressure; blue collar; cardiovascular disease; cohort study; Copenhagen Heart Study; heavy lifting; hypertension; lifting; manual handling; occupational epidemiology; occupational lifting; occupational physical activity; prospective association; prospective study

This article in PubMed: www.ncbi.nlm.nih.gov/pubmed/31454050

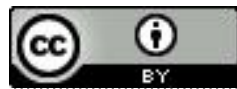




\title{
Does occupational lifting affect the risk of hypertension? Cross-sectional and prospective associations in the Copenhagen City Heart Study
}

\author{
by Mette Korshøj, PhD, ${ }^{1}$ Harald Hannerz, PhD, ${ }^{1}$ Jacob L Marott, PhD, ${ }^{2}$ Peter Schnohr, PhD, ${ }^{2}$ Eva Prescott, PhD, ${ }^{2,3}$ \\ Els Clays, PhD, ${ }^{4}$ Andreas Holtermann, PhD ${ }^{1,5}$
}

\begin{abstract}
Korshøj M, Hannerz H, Marott JL, Schnohr P, Prescott E, Clays E, Holtermann A. Does occupational lifting affect the risk of hypertension? Cross-sectional and prospective associations in the Copenhagen Heart Study. Scand J Work Environ Health. 2020;46(2):188-197. doi:10.5271/sjweh.3850
\end{abstract}

Objective The aim of this study was to investigate cross-sectional and prospective associations between heavy occupational lifting and hypertension.

Methods Data from the third, fourth and fifth examinations of the Copenhagen City Heart Study were included. Multivariable logistic regression models were applied to adjust for sex, age, body mass index (BMI), smoking, education, self-rated cardiorespiratory fitness, vital exhaustion and baseline blood pressure, and were used to estimate (i) the cross-sectional association between heavy occupational lifting and hypertension, defined as using anti-hypertensives or having a systolic blood pressure (SBP) $\geq 140 \mathrm{mmHg}$ or diastolic blood pressure (DBP) $\geq 90$ $\mathrm{mmHg}$, and (ii) the prospective association between heavy occupational lifting and risk of becoming a systolic blood pressure case, defined as an above median change (from baseline to follow-up) and/or a shift from no use of anti-hypertensives at baseline to use of anti-hypertensives at a ten-year follow-up.

Results Both cross-sectional [odds ratio (OR) 1.06, 95\% confidence interval (CI) $0.94-1.20$ ] and prospective (OR 1.10, 95\% CI 0.92-1.31) analysis indicated no relations. Explorative prospective analyses suggested linear associations between heavy occupational lifting and systolic blood pressure among participants using antihypertensives. Exposure to heavy occupational lifting tended to increase the incidence of hypertension (OR 1.30, $95 \%$ CI $0.97-1.73$ ) among participants $\geq 50$ years.

Conclusions No associations were seen among the general population. Positive associations were seen among users of anti-hypertensives and participants $\geq 50$ years, indicating these groups as vulnerable to increases in blood pressure when exposed to occupational lifting.

Key terms blood pressure; blue collar; cardiovascular disease; cohort study; heavy lifting; manual handling; occupational epidemiology; occupational physical activity.

Recent surveys have concluded that heavy occupational lifting is described as a risk for low-back pain (1), however heavy lifting also affects the cardiovascular system through acute increases in blood pressure (BP) (2). Some workers perform occupational lifting for several hours per day, many days per week, and therefore may be at risk for developing hypertension due to the frequency and duration of acutely increased BP (3). Thus heavy occupational lifting may act as an occupational risk factor for hypertension $(4,5)$. The prevalence of hypertension varies across occupational groups, supporting the impact by the working environment (6). Hypertension is a major preventable cardiovascular risk factor (7-9) and is estimated to cause $14 \%$ of all annual deaths globally (10). However, only few studies $(4,5,11)$ have investigated the relation between heavy occupational lifting and hypertension, showing conflicting results. Thus, investigating these associations could reveal a potential for prevention of hypertension, especially among the $22 \%$ of the Danish workforce and $32 \%$ of European workers estimated to be

1 National Research Centre for the Working Environment, Copenhagen, Denmark.

2 Copenhagen City Heart Study, Bispebjerg Frederiksberg Hospital, University of Copenhagen, Copenhagen, Denmark.

3 Department of Cardiology, Bispebjerg Frederiksberg Hospital, University of Copenhagen, Copenhagen, Denmark.

4 Department of Public Health and Primary Care, Ghent University, Ghent, Belgium.

5 Department of Sports Science and Clinical Biomechanics, University of Southern Denmark, Odense, Denmark. 
exposed to heavy occupational lifting on a regular basis (12) (6 $6^{\text {th }}$ survey in Eurofound).

This study's objective was to explore associations between heavy occupational lifting and hypertension in the Copenhagen City Heart Study, with the hypothesis that heavy occupational lifting is associated with a higher prevalence of hypertension and an increased incidence of new-onset hypertension in normotensives.

\section{Methods}

A detailed protocol for this study has been reported elsewhere (13). Briefly, randomly selected Copenhagen citizens, aged $\geq 20$ years, were examined in the Copenhagen City Heart Study, containing person-based information on health as well as a large variety of biological, environmental and lifestyle-related factors (14). Data from the third (1991-94, response rate 61.2\%), fourth (2001-03, response rate 49.5\%) and fifth (2011-15, response rate $46.6 \%$ ) examination were included in this study. Thus, the cross-sectional analysis had a possibility of three observations per participant, and the prospective analysis had possibility of two observations per participant.

\section{Inclusion criteria}

All participants with data on BP, level of occupational physical activity (OPA) (including heavy lifting) and use of anti-hypertensives were included in the crosssectional analysis.

All normotensive participants with data on level of OPA at the third and/or fourth examination (n) and data on BP and use of anti-hypertensives in examination ( $\mathrm{n}$ and $n+1$ ) were included in the prospective analysis.

\section{Assessment of heavy lifting}

Self-reported level of OPA was obtained by use of the same question in all three examinations: "Please describe your level of occupational physical activity within the past year" with the following response categories:" (i) predominantly sedentary; (ii) sitting or standing, some walking; (iii) walking, some handling of material; (iv) heavy manual work". If answering iii or iv, an additional question regarding heavy occupational lifting was applied: "Do you lift heavy burdens?" with the response categories: yes or no. In the analysis, the participants were classified as exposed to heavy occupational lifting by answering "yes" to the question concerning heavy burdens, and those participants answering i, ii and iii or iv in combination with not lifting heavy burdens were set as the reference group.
No information was collected in between examinations. In the prospective analysis, the stability of exposure was accounted for by cross-tabulating the self-reported exposure at examination three by exposure at examination four, and also the self-reported exposure at examination four by exposure at examination five. An evaluation of the agreement (Cohen's kappa) between exposures to heavy occupational lifting across the examinations showed fair agreement (13), and thus the baseline exposure were regarded as valid and used throughout.

\section{Definition of hypertension}

Hypertension, the primary outcome measure, was defined as reported use of anti-hypertensives or a measured systolic blood pressure (SBP) $\geq 140 \mathrm{mmHg}$ or diastolic blood pressure (DBP) $\geq 90 \mathrm{mmHg}$ (15) in the cross-sectional analysis. In the prospective analysis, hypertension was defined as the shift from from no use of anti-hypertensives in examination (n) to use of antihypertensives in examination $(\mathrm{n}+1)$ or an above median delta value of SBP [SBP in examination $(n+1)-S B P$ in examination (n)]. Additionally, pulse pressure (PP) (PP $=\mathrm{SBP}-\mathrm{DBP})$, mean arterial pressure $(\mathrm{MAP})(\mathrm{MAP}=$ $(2 \times \mathrm{DBP}+\mathrm{SBP}) / 3))$ and mid $\mathrm{BP}(1 / 2 \mathrm{SBP}+1 / 2 \mathrm{DBP})$ were investigated as secondary outcomes.

$\mathrm{BP}$ was measured according to the WHO guidelines recommended by Rose \& Blackburn (16). Using a London School of Hygiene sphygmomanometer (17), BP was measured one time on the non-dominant arm after 5 -minute sitting rest. The fall of the mercury column was set to $2 \mathrm{~mm} / \mathrm{s}$. The specially trained technicians were instructed in the same way, and all conditions during the measurements were identical at all examinations.

\section{Assessment of covariates}

A number of factors have previously been shown to be associated both with exposure to OPA, such as occupational lifting, and BP. Thus, the following factors were included as covariates: sex (male/female) (18); age $(<40,40-49,50-59,60-69,70-79,>80$ years) $(19)$; body mass index (BMI) $(<18.5,18.5-24.9,25.0-29.9$, $\left.\geq 30 \mathrm{~kg} / \mathrm{m}^{2}\right)(20)$ calculated from measured body height and weight; smoking (non-smoking; currently smoking) (21); length of education (no formal education; low educated up to 3 years; vocationally educated 1-3 years; higher educated; academically educated) (22); and, for the prospective analysis only, additional adjustment for vital exhaustion, split in four categories defined elsewhere $(0,1-4,5-9,10-17)(23)$; self-rated cardiorespiratory fitness (lower, similar, higher cardiorespiratory fitness compared to peers of same sex and age) (24); SBP at baseline $(80-89,90-99,100-109$, 
110-119, 120-129, 130-139, $\geq 140 \mathrm{mmHg})(25)$, and DBP at baseline $(40-49,50-59,60-69,70-79,80-89$, $\geq 90 \mathrm{mmHg}$ ).

\section{Statistical analyses}

The primary null-hypothesis for the cross-sectional analysis was that heavy occupational lifting is not associated to hypertension, defined as using anti-hypertensives or having a measured SBP $\geq 140 \mathrm{mmHg}$ or DBP $\geq 90 \mathrm{mmHg}$. In the prospective analysis, the primary null-hypothesis was that heavy occupational lifting at baseline does not increase the incidence of new-onset hypertension in normotensives.

The overall significance level was set at 0.05 . However, Bonferroni corrections were applied meaning that the two primary hypotheses were tested at a significance level of 0.025 (13). The exploratory secondary analyses were not tested for statistical significance but reported by $95 \%$ confidence interval $(\mathrm{CI})$.

\section{Primary analyses}

In the cross-sectional and prospective analyses, as a function of heavy occupational lifting, the odds of being hypertensive and becoming a SBP case, respectively, were estimated using logistic regression in a generalized estimating equation (GEE) model, with no exposure to heavy occupational lifting as reference. Observations from the same person were treated as repeated measurements. A first order autoregressive correlation structure was assumed. The cross-sectional analysis was controlled for sex, age, BMI, smoking and education. In addition, the prospective analysis was controlled for self-rated cardiorespiratory fitness, vital exhaustion, and $\mathrm{BP}$ at baseline.

\section{Secondary analyses}

Linear regressions. The associations between heavy occupational lifting and SBP, DBP, PP and MAP ( $\mathrm{mmHg}$ ) were

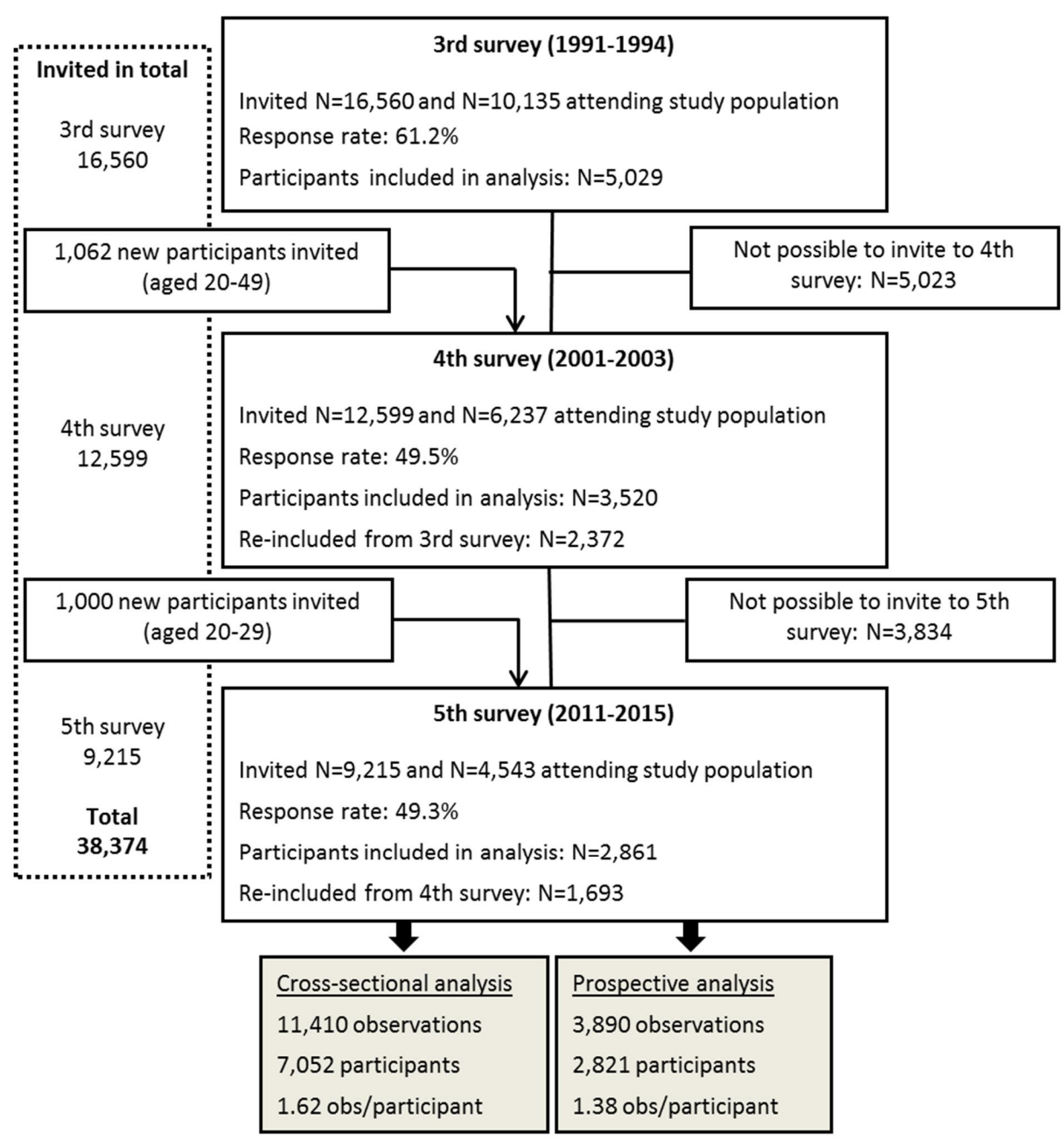

Figure 1. Flow of the observations and participantsinthethird, fourth andfifthexamination of theCopenhagen City Heart Study. 
investigated, first cross-sectionally and then prospectively (change in $\mathrm{mmHg}$ from examination $\mathrm{n}$ to examination $\mathrm{n}+1$ ), by use of linear regression models. These linear regressions were applied to both the entire included population as well as a population excluding those participants who reported to use anti-hypertensives.

Sensitivity to choice of comparison group. To investigate how sensitive the adjusted primary analyses were to the choice of comparison group, we performed an additional linear regression with SBP as outcome only. Here the comparison group was split into three different subgroups according to the self-reported categories of OPA, thus an exposure variable with four instead of two categories was created.

Sensitivity to the definition of hypertension. Due to the variety in cut-points for defining hypertension [SBP $\geq 160$ $\mathrm{mmHg}$ or $\mathrm{DBP} \geq 100 \mathrm{mmHg}$ (14); $\mathrm{SBP} \geq 180 \mathrm{mmHg}$ or $\mathrm{DBP} \geq 110 \mathrm{mmHg}(15,26)$ or SBP $\geq 130 \mathrm{mmHg}$ or DBP $\geq 80 \mathrm{mmHg}$ (25)], we investigated whether the OR for hypertension as a function of heavy occupational lifting was sensitive to the cut-point for defining hypertension. Thus, two additional cross-sectional logistic regression analyses were conducted using alternative cut-points: $\mathrm{SBP} \geq 160 \mathrm{mmHg}$ or $\mathrm{DBP} \geq 100 \mathrm{mmHg}$ and $\mathrm{SBP} \geq 130$ $\mathrm{mmHg}$ or $\mathrm{DBP} \geq 80 \mathrm{mmHg}$.

Stratification by age. Due to the lack of occupational exposures as a result of old age pension ( 65 years) and/ or early retirement (60 years) at the follow-up examination, analysis similar to the primary analysis stratified by age at baseline ( $\geq$ versus $<50$ years) were performed.

\section{Results}

From examination three, 5106 observations were excluded: 2717 from examination four and 1689 from examination five. Hence, 7052 and 4014 participants were included in the cross-sectional and prospective analyses, respectively (figure 1 and table 1).

\section{Primary analysis}

The crude primary cross-sectional analysis showed that those performing heavy occupational lifting had

Table 1. Baseline characteristics of the included participants for the cross-sectional analysis; 11410 observations on 7052 participants, and for the prospective analysis; 3890 observations on 2821 participants. [MVPA=moderate-to-vigorous physical activity; SD=standard deviation.]

\begin{tabular}{|c|c|c|c|c|c|c|c|c|}
\hline & \multicolumn{4}{|c|}{ Cross-sectional analysis } & \multicolumn{4}{|c|}{ Prospective analysis } \\
\hline & Mean & SD & $\mathrm{N}(\%)$ & Range & Mean & SD & $\mathrm{N}(\%)$ & Range \\
\hline Age (years) & 48.9 & 13.7 & & $20.3-93.4$ & 45.4 & 11.7 & & $20.3-81.9$ \\
\hline Sex (female) & & & $6201(54.3)$ & & & & $2341(60.2)$ & \\
\hline BMI $\left(\mathrm{kg} / \mathrm{m}^{2}\right)$ & 25.2 & 4.2 & & $12.8-56.6$ & 24.2 & 3.6 & & $16.0-48.4$ \\
\hline Smoking (current smokers) & & & $4211(36.9)$ & & & & $1520(39.1)$ & \\
\hline Systolic blood pressure (mmHg) & 131.1 & 19.6 & & $77.0-240.0$ & 119.2 & 10.6 & & $82.0-139.0$ \\
\hline Diastolic blood pressure (mmHg) & 80.4 & 11.9 & & $33.0-154.0$ & 74.9 & 8.3 & & $42.0-89.0$ \\
\hline Blood pressure $\geq 90 / \geq 140 \mathrm{mmHg}$ & & & $4018(35.2)$ & & & & & \\
\hline Using anti-hypertensive medication & & & $1117(9.8)$ & & & & $86(2.2)$ & \\
\hline Using diuretic medication & & & $477(4.2)$ & & & & $68(1.7)$ & \\
\hline $\begin{array}{l}\text { Hypertensive ( } \geq 90 / \geq 140 \mathrm{mmHg} \text { or using } \\
\text { anti-hypertensive medication) }\end{array}$ & & & 4309 (37.8) & & & & & \\
\hline $\begin{array}{l}\text { Hypertensive ( } \geq 80 / \geq 130 \mathrm{mmHg} \text { or using } \\
\text { anti-hypertensive medication) }\end{array}$ & & & $7211(63.2)$ & & & & & \\
\hline $\begin{array}{l}\text { Hypertensive ( } \geq 100 / \geq 160 \mathrm{mmHg} \text { or using } \\
\text { anti-hypertensive medication) }\end{array}$ & & & $2131(18.7)$ & & & & & \\
\hline \multicolumn{9}{|l|}{ Education (years) } \\
\hline No formal education & & & $1577(13.8)$ & & & & $461(11.8)$ & \\
\hline Low educated $(<3)$ & & & $1767(15.5)$ & & & & $1490(38.3)$ & \\
\hline Vocational education $(1-3)$ & & & $3069(26.9)$ & & & & $1194(30.7)$ & \\
\hline Higher education $(>3)$ & & & $2051(18.0)$ & & & & $260(6.7)$ & \\
\hline Academic education & & & $2770(24.3)$ & & & & $402(10.3)$ & \\
\hline \multicolumn{9}{|l|}{ Occupational physical activity } \\
\hline Predominantly sedentary & & & $4294(37.6)$ & & & & $1445(37.1)$ & \\
\hline Sitting or standing, some walking & & & $3992(35.0)$ & & & & $1329(34.2)$ & \\
\hline Walking, some handling of material & & & $2683(23.5)$ & & & & $990(25.4)$ & \\
\hline Heavy manual work & & & $441(3.9)$ & & & & $126(3.2)$ & \\
\hline Occupational heavy lifting (yes) & & & $1795(15.7)$ & & & & $664(17.1)$ & \\
\hline \multicolumn{9}{|l|}{ Leisure time physical activity (hours/week) } \\
\hline Inactive/light physical active (<2) & & & $983(8.6)$ & & & & $281(7.2)$ & \\
\hline Light physical active (2-4) & & & $5319(46.6)$ & & & & $1899(48.8)$ & \\
\hline Light physical active (>4) or MVPA (2-4) & & & $4378(38.4)$ & & & & 1499 (38.5) & \\
\hline MVPA (>4) & & & $699(6.1)$ & & & & $205(5.3)$ & \\
\hline Vital exhaustion (sum, 0-17) & 3.0 & 3.5 & & $0-17$ & 2.9 & 3.3 & & $0.0-17.0$ \\
\hline Cardiorespiratory fitness (similar to peers) & & & $6272(55.0)$ & & & & $2235(57.5)$ & \\
\hline Observation per participant & 1.6 & & & $1-3$ & 1.4 & & & $1-2$ \\
\hline
\end{tabular}


Table 2. Crude and adjusted odd ratios (OR) of prevalence of being hypertensive (in the cross-sectional model) and for becoming a systolic blood pressure (BP) case (in the prospective model) by self-rated exposure to heavy occupational lifting. No exposure to heavy occupational lifting was reference. All models include a repeated statement. [Cl=confidence interval.]

\begin{tabular}{|c|c|c|c|c|c|c|c|c|}
\hline \multirow[t]{2}{*}{ Heavy occupational lifting } & \multicolumn{4}{|c|}{ Crude model } & \multicolumn{4}{|c|}{ Adjusted model } \\
\hline & $\mathrm{N}$ & $\mathrm{OR}$ & $95 \% \mathrm{Cl}$ & P-value & $\mathrm{N}$ & OR & $95 \% \mathrm{Cl}$ & P-value \\
\hline Cross-sectional hypertensive ${ }^{a}$ & 11410 & 1.12 & $1.01-1.24$ & 0.04 & 11039 & 1.06 & $0.94-1.20$ & 0.34 \\
\hline Prospective systolic case ${ }^{b}$ & 3890 & 1.11 & $0.95-1.30$ & 0.19 & 3668 & 1.10 & $0.92-1.31$ & 0.29 \\
\hline Prospective diastolic case ${ }^{b}$ & 3890 & 1.11 & $0.95-1.31$ & 0.18 & 3668 & 1.06 & $0.88-1.27$ & 0.54 \\
\hline
\end{tabular}

${ }^{a}$ The cross-sectional model is adjusted for sex, age, BMI, smoking and education.

${ }^{\mathrm{b}}$ The prospective model is adjusted for sex, age, body mass index, smoking, education, self-rated cardiorespiratory fitness, vital exhaustion and BP at baseline.

Table 3. Adjusted associations between self-reported heavy occupational lifting and systolic blood pressure (BP) (mmHg), diastolic BP $(\mathrm{mmHg})$, pulse pressure $(\mathrm{mmHg})$ and mean arterial pressure $(\mathrm{mmHg})$, stratified on use of anti-hypertensive. Occupational physical activity groups are clustered by answering "yes" or "no" to exposure to heavy occupational lifting; "yes" are in the heavy lifting category and "no" are divided in the other categories set by their self-reported level of occupational physical activity where the categories of walking, some handling of material AND heavy manual work, but no heavy lifting are collapsed. [Cl=confidence interval.]

\begin{tabular}{lcclccc}
\hline \multirow{2}{*}{$\begin{array}{l}\text { Heavy occupational } \\
\text { lifting }\end{array}$} & \multicolumn{2}{c}{ Cross-sectional $^{\mathrm{a}}$} & & \multicolumn{3}{c}{ Prospective $^{\mathrm{b}}$} \\
\cline { 2 - 3 } \cline { 5 - 6 } & $\beta(\mathrm{mmHg})$ & $95 \% \mathrm{Cl}$ & & $\beta(\mathrm{mmHg})$ & $95 \% \mathrm{Cl}$ \\
& & & & & \\
\hline NOT using & 9945 observations & & \multicolumn{2}{c}{3589 observations } \\
anti-hypertensives & \multicolumn{2}{c}{6574 participants } & & 2752 participants \\
Systolic BP & 0.45 & $-0.45-1.35$ & & -0.08 & $-1.29-1.14$ \\
Diastolic BP & 0.34 & $-0.25-0.94$ & & -0.02 & $-0.84-0.81$ \\
Pulse pressure & 0.12 & $-0.59-0.83$ & & 0.01 & $-1.04-1.07$ \\
Mean arterial pressure & 0.36 & $-0.26-0.99$ & & -0.03 & $-0.87-0.80$ \\
USING anti-hypertensives & 1096 observations & & 84 observations \\
& 967 participants & & 79 participants \\
Systolic BP & -1.98 & $-5.22-1.26$ & & 15.91 & $5.30-26.52$ \\
Diastolic BP & -0.38 & $-2.43-1.67$ & & 4.02 & $-2.21-10.27$ \\
Pulse pressure & -1.59 & $-4.44-1.27$ & & 7.87 & $-0.06-15.80$ \\
Mean arterial pressure & -0.94 & $-3.05-1.18$ & & 7.46 & $0.67-14.24$ \\
\hline
\end{tabular}

${ }^{a}$ Adjusted for sex, age, body mass index, smoking and education.

${ }^{\mathrm{b}}$ Adjusted for sex, age, body mass index, smoking, education, self-rated cardiorespiratory fitness, vital exhaustion and BP at baseline.

a $12 \%$ higher prevalence for hypertension than the non-exposed. However, when adjusting for relevant confounders, heavy occupational lifting did not affect the prevalence of hypertension (table 2). The prospective models did not show significantly increased risks for becoming a SBP or DBP case when exposed to heavy occupational lifting (table 2).

\section{Secondary analyses}

Linear regressions. Secondary analyses were performed by linear regressions to investigate the differences in SBP, DBP, PP, and MAP between participants exposed, or not, to heavy occupational lifting (13). The linear regressions relating heavy occupational lifting to $\mathrm{BP}$ showed no significant associations with any of the BP outcomes either in the cross-sectional or in the prospective analyses (supplementary material, www.sjweh.fi/ show abstract.php?abstract id $=3850$, table S1). The linear regressions relating heavy occupational lifting to BP, stratified on use of anti-hypertensives, showed that, among participants not using anti-hypertensives, no significant associations between heavy occupational lifting and any of the BP outcomes neither cross-sectionally nor prospectively were seen (table 3 ). Also among users of anti-hypertensives no significant associations were seen cross-sectionally (table 3 ). However, positive associations between heavy occupational lifting and SBP and MAP were seen prospectively among users of antihypertensives (table 3 ).

\section{Sensitivity to choice of comparison group}

By stratifying the participants by their self-reported level of OPA the sensitivity to choice of comparison group of the secondary linear regression was tested. However, this analysis did not show any significant associations neither in the cross-sectional nor the prospective analysis (supplementary file, table S2).

\section{Sensitivity to definition of hypertension}

The sensitivity analyses applying cut-points for the definition of hypertension being higher (SBP $\geq 160 \mathrm{mmHg}$ or $\mathrm{DBP} \geq 100 \mathrm{mmHg}$ ) and lower (SBP $\geq 130 \mathrm{mmHg}$ or DBP $\geq 80 \mathrm{mmHg}$ ) than the cut-point used in the primary analysis ( $\mathrm{SBP} \geq 140 \mathrm{mmHg}$ or $\mathrm{DBP} \geq 90 \mathrm{mmHg}$ ), showed that the OR for being hypertensive as a function of heavy occupational lifting was sensitive to the cut-points for definition of hypertension. By application of the higher cut-points, no relation between risk for hypertension and heavy occupational lifting was seen (OR $0.96,95 \%$ CI 0.82-1.11), whereas the lower cut-points showed a tendency towards an increased OR for being hypertensive when exposed to heavy occupational lifting (OR 1.13, 95\% CI 0.99-1.28). 
Table 4. Adjusted odd ratios (OR) for being hypertensive, in the cross-sectional model, and for becoming a systolic blood pressure (BP) case, in the prospective model, stratified on age at baseline ( $\geq$ versus $<50$ years). No exposure to heavy occupational lifting was reference. All models include a repeated statement. [Cl=confidence interval.]

\begin{tabular}{|c|c|c|c|c|c|c|c|c|}
\hline \multirow[t]{2}{*}{ Heavy occupational lifting } & \multicolumn{4}{|c|}{ Age $\geq 50$ years } & \multicolumn{4}{|c|}{ Age $<50$ years } \\
\hline & $\mathrm{N}$ & OR & $95 \% \mathrm{Cl}$ & P-value & $\mathrm{N}$ & OR & $95 \% \mathrm{Cl}$ & P-value \\
\hline Cross-sectional hypertensive ${ }^{a}$ & 5670 & 1.06 & $0.90-1.24$ & 0.50 & 5371 & 1.09 & $0.90-1.32$ & 0.36 \\
\hline Prospective systolic case ${ }^{b}$ & 1435 & 1.22 & $0.90-1.66$ & 0.20 & 2233 & 1.03 & $0.83-1.30$ & 0.77 \\
\hline Prospective diastolic case ${ }^{b}$ & 1435 & 1.30 & $0.97-1.73$ & 0.08 & 2233 & 0.94 & $0.74-1.19$ & 0.59 \\
\hline
\end{tabular}

adjusted for sex, age, body mass index, smoking and education.

${ }^{\mathrm{b}}$ Adjusted for sex, age, body mass index, smoking, education, self-rated cardiorespiratory fitness, vital exhaustion and BP at baseline.

\section{Age stratified analysis}

The cross-sectional and prospective analyses among both participants $<50$ and $\geq 50$ years old showed that heavy occupational lifting did not affect the odds for being hypertensive or becoming a SBP or DBP case (table 4). However, a tendency of an increased risk for becoming a DBP case was seen among participants $\geq 50$ years old.

\section{Discussion}

This study aimed to investigate cross-sectional and prospective relations between heavy occupational lifting and hypertension. Neither the cross-sectional nor the prospective analysis could reject the primary nullhypothesis of no effect of heavy occupational lifting on the prevalence nor incidence of hypertension since non-significant increases in the prevalence and incidence of hypertension by $6 \%$ and $10 \%$, were seen (table 2). The secondary analyses showed large rises in BP $(\triangle \mathrm{SBP}$ $16 \mathrm{mmHg}, 95 \%$ CI $5-27 \mathrm{mmHg}$, and $\triangle \mathrm{MAP} 7 \mathrm{mmHg}$, 95\% CI $1-14 \mathrm{mmHg}$, table 3 ) among participants using anti-hypertensives when exposed to heavy occupational lifting. Another sensitivity analysis indicated that participants aged $\geq 50$ years were at $30 \%$ increased risk (OR $1.30,95 \%$ CI $0.97-1.73$ ) for becoming a DBP case when exposed to heavy occupational lifting. Further investigations of these associations are therefore warranted for prevention of hypertension, particularly across older workers and workers using anti-hypertensives.

These indications of increases in BP can be explained by the acutely increasing effect on BP from lifting, due to the acute increases in total peripheral resistance from the occlusion of vessels by the static muscle activity (2, 28). However, longitudinal studies show that leisure time resistance training lowers BP $(29,30)$, which may be explained by the physiologic adaptations in the cardiorespiratory system, taking place during restitution, leading to beneficial effects as increased cardiorespiratory fitness (28). Yet, the lack of these beneficial effects from OPA could be explained by the insufficient recovery due to the high frequency (5 days a week) and long duration (7-9 hours per day) $(31,32)$. Across some occupations, heavy occupational lifting is a part of OPA, and could therefore prospectively raise $\mathrm{BP}$ due to the high frequency and duration of lifting combined with an insufficient recovery (3). However, studies investigating the relation between heavy occupational lifting and $\mathrm{BP}$ are few and conflicting $(4,5,33)$.

One major challenge in this research field is the healthy worker selection, described as workers migrating away from occupations with high OPA into more sedentary occupations (34). This selection could be based on symptoms of deteriorated health, eg, angina pectoris. Hypertension could be seen as non-symptomatic, however high SBP are thought to impact risk for angina (35). Future analysis should therefore investigate relations between heavy occupational lifting and risk factors for cardiovascular disease (CVD) by use of nonsymptomatic outcomes or precursors of hypertension to bypass the healthy worker selection.

The secondary analyses revealed two sub-groups: users of anti-hypertensives and participants aged $\geq 50$ years as being particularly vulnerable for exposure to heavy occupational lifting.

The prospective linear associations relating heavy occupational lifting to BP, stratified on use of antihypertensives, showed large rises in BP $(\triangle \mathrm{SBP} 16$ $\mathrm{mmHg}, 95 \%$ CI 5-27 mmHg, and $\triangle \mathrm{MAP} 7 \mathrm{mmHg}, 95 \%$ CI 1-14 mmHg, table 3) among users of these medications. Additionally, the $95 \% \mathrm{CI}$ for the prospective linear relations between heavy occupational lifting and $\triangle \mathrm{DBP}$ and $\triangle \mathrm{PP}$ likewise indicated clinically relevant hazardous increases (25). These increases in BP may be explained by these participants being more susceptible to having a low compliance in the arteries due to decreased elasticity caused by the endothelia damage from the increased level of mean arterial pressure (36) initially causing the use of anti-hypertensives. Low arterial compliance decreases the ability of the arteries to dilate sufficiently when the blood are being pumped from the heart, this combined with occlusion of the vessels during static activities, such as lifting, will lead to major increases of the BP (28). 
The estimated OR from the analysis stratified by age ( $<>\geq 50$ years) showed tendencies of stronger associations between heavy lifting and hypertension among participants aged $\geq 50$ years (OR of becoming a SBP case of 1.22 and a DBP case of 1.30) compared to among participants aged $<50$ years (1.03 and 0.94) (table 4). This can be explained by the age and health-dependent decreases in aerobic capacity, leading to increased cardiorespiratory load from performing heavy occupational lifting (37). Also, the age-dependent loss of compliance in the arteries contributes to increases in BP due to the increased total peripheral resistance $(28,38)$.

The literature proposes differences in cut-points for being classified as hypertensive $(15,26,27)$, and therefore two additional cut-points of hypertension [SBP $\geq 160 \mathrm{mmHg}$ or DBP $\geq 100 \mathrm{mmHg}(15,26)$ and SBP $\geq 130 \mathrm{mmHg}$ or DBP $\geq 80 \mathrm{mmHg}$ (27)] were applied to the cross-sectional analyses. These sensitivity analyses showed that the OR for being hypertensive as a function of heavy occupational lifting seemed to be sensitive to the choice of cut-point; the cut-point of SBP $\geq 130$ $\mathrm{mmHg}$ or $\mathrm{DBP} \geq 80 \mathrm{mmHg}$ yielded an OR of 1.13 , whereas the cut-point of SBP $\geq 160 \mathrm{mmHg}$ or $\mathrm{DBP} \geq 100$ $\mathrm{mmHg}$ yielded an OR of 0.96 , and the cut-point of SBP $\geq 140 \mathrm{mmHg}$ or DBP $\geq 90 \mathrm{mmHg}$ yielded an OR of 1.06 .

Taken together, this paper contributes to the knowledge of risk for hypertension from heavy occupational lifting and sheds light on the need for specific attention among those performing heavy occupational lifting while using anti-hypertensives (25). These results could therefore feed into prevention initiatives of hypertension specifically targeted workers exposed to heavy occupational lifting.

\section{Methodological challenges}

These analyses should be interpreted in light of the present limitations: the self-reported exposure to heavy occupational lifting and level of cardiorespiratory fitness might be affected by recall bias $(39,40)$; self-reported data are only collected from participants at the examinations, which could add a selection bias to the collected data. To collect exposures of heavy lifting independently of participation, future studies could consider receiving the exposure data from job exposure matrices, additionally could the recall bias be bypassed by use of technical measures of exposure to heavy occupational lifting. The collection of BP only in consultation during rest gives a lower prognostic value than obtained by monitoring of 24 hours BP or BP during sleep $(41,42)$; and the lowered odds for having prolonged working hours when exposed to heavy occupational lifting (33), which was not possible to adjust for in the present analysis due to the lacking information of amount of weekly working hours. Future studies investigating these relations could consider collecting the exposure information by use of a job exposure matrix or technical measures, not holding the limitations of being self-reported.

However, the analysis also holds some strengths; the follow-up time of 8-10 years and the determination of hypertension based both on use of prescription medicine and the resting $\mathrm{BP}$ in $\mathrm{mmHg}$, limiting the risk of classifying participant as false negative. Also the randomly selected study population is a strength as well as the inclusion criteria of no use of anti-hypertensives, as these medications potentially may conceal, reverse or otherwise distort effects of heavy occupational lifting on BP. In line with this, participants diagnosed with hypertension at baseline were excluded from the prospective analysis because they were likely to receive anti-hypertensive medication in the in the time period between examinations. On the other hand, exclusion of those participants being diagnosed as hypertensive and/ or using anti-hypertensives decreases variability of the analyzed population towards a more healthy population and thereby lacks the potential of investigating the effects of heavy occupational lifting among a population proposedly at higher risk for cardiovascular endpoints (31).

\section{Implications of the results}

Heavy lifting acutely increases BP (2). Approximately $22 \%$ of Danish workers and $32 \%$ of European workers are regularly exposed to heavy occupational lifting (12) ( $6^{\text {th }}$ survey in Eurofound), and due to the frequency and duration of the occupational lifting, it is likely that increases in BP and hypertension will occur (3). Hypertension is a major risk factor for CVD and mortality (7, $8,10)$. In spite of this, the Danish Working Environment Authority guideline for occupational lifting from 2005 (arbejdstilsynet.dk/da/regler/at-vejledninger/1/d-31-loft-traek-og-skub) only concerns risk factors for musculoskeletal disorders. Therefore we conducted this study to feed into the discussion on cardiovascular risk factors from heavy occupational lifting. This study finds that the prevalence and incidence of hypertension, to some extent, may increase by exposure to heavy occupational lifting. Although these OR are uncertain, the indications of rises in risk for hypertension up to $10 \%$ might still be of preventive importance for the general working population.

Secondly, the results showed that workers using anti-hypertensives would be expected to experience rises in SBP - from exposure to heavy occupational lifting - by $16 \mathrm{mmHg}$, which indicates a major increase in CVD risk $(7,9,25)$. Also older workers (aged $\geq 50$ years old at baseline) seemed to be more vulnerable to developing hypertension from exposure to heavy occupational lifting than younger workers (aged $<50$ years 
old at baseline). Hence, exposure to heavy occupational lifting could impact the workability as well as employability among workers aged $\geq 50$ years old or those who use anti-hypertensives due to the fact that high SBP are thought to impact risk for angina (35), and thereby migration from occupations exposed to heavy occupational lifting to occupations with more light physical activity levels. Thus, it could be considered that tailoring the exposure to heavy occupational lifting to the age and general health of the worker would impact risk for hypertension and work sustainability beneficially.

These results suggest that the risk for hypertension might be lowered by reducing the exposure to heavy occupational lifting, especially among workers using anti-hypertensives and aged $\geq 50$ years. These results are drawn among participants who showed up at examinations in a randomly selected adult Danish population and since the work environmental laws and regulations of occupational lifting are the same in the entire nation, we believe that the result of the study to some extent may be generalized to the entire Danish workforce. Yet, these conclusions are solely based on those who participated in examinations and, thus, a future investigation of this association might benefit from a study design not dependent on participation, such as a job exposure matrix. Nonetheless, knowledge is still needed to verify these findings and also to investigate the effect of accumulation of exposure from heavy occupational lifting on hypertension. Future studies investigating these relations could consider collecting the exposure information by use of job exposure matrices or technical measures, without the limitations of being self-reported.

\section{Concluding remarks}

No associations between heavy occupational lifting and prevalence and incidence of hypertension were seen among the general population. The secondary analyses showed positive associations between heavy occupational lifting and risk of hypertension among two vulnerable sub-groups, ie, (i) users of anti-hypertensives, and (ii) workers aged $\geq 50$ years. Yet, these conclusions should be interpreted with the methodological limitations of this study in mind, and therefore further research is needed to confirm these associations.

\section{Conflicts of interest}

None declared.

\section{Acknowledgements}

The project is funded by the Danish tax payers, via the Danish Work Environment Research Foundation, grant number 20150067515. We would also like to thank Niklas Krause for valuable discussions.

\section{References}

1. Coenen P, Gouttebarge V, van der Burght AS, van Dieën $\mathrm{JH}$, Frings-Dresen MH, van der Beek AJ et al. The effect of lifting during work on low back pain: a health impact assessment based on a meta-analysis. Occup Environ Med 2014 Dec;71(12):871-7. https://doi.org/10.1136/ oemed-2014-102346.

2. MacDougall JD, Tuxen D, Sale DG, Moroz JR, Sutton JR Arterial blood pressure response to heavy resistance exercise. J Appl Physiol (1985). 1985;58(3):785-90.

3. Clays E, De Bacquer D, Van Herck K, De Backer G, Kittel F, Holtermann A. Occupational and leisure time physical activity in contrasting relation to ambulatory blood pressure. BMC Public Health 2012 Nov;12:1002. https://doi. org/10.1186/1471-2458-12-1002.

4. Fransson E, De Faire U, Ahlbom A, Reuterwall C, Hallqvist J, Alfredsson L. The risk of acute myocardial infarction: interactions of types of physical activity. Epidemiology 2004 Sep;15(5):573-82. https://doi.org/10.1097/01. ede.0000134865.74261.fe.

5. Petersen CB, Eriksen L, Tolstrup JS, Søgaard K, Grønbaek M, Holtermann A. Occupational heavy lifting and risk of ischemic heart disease and all-cause mortality. BMC Public Health 2012 Dec;12:1070. https://doi.org/10.1186/14712458-12-1070

6. Kristensen TS. Cardiovascular diseases and the work environment. A critical review of the epidemiologic literature on nonchemical factors. Scand J Work Environ Health 1989 Jun;15(3):165-79. https://doi.org/10.5271/ sjweh.1864.

7. He J, Whelton PK. Elevated systolic blood pressure and risk of cardiovascular and renal disease: overview of evidence from observational epidemiologic studies and randomized controlled trials. Am Heart J 1999 Sep;138(3 Pt 2):211-9. https://doi.org/10.1016/S0002-8703(99)70312-1.

8. Antikainen RL, Moltchanov VA, Chukwuma C Sr, Kuulasmaa KA, Marques-Vidal PM, Sans S et al.; WHO MONICA Project. Trends in the prevalence, awareness, treatment and control of hypertension: the WHO MONICA Project. Eur J Cardiovasc Prev Rehabil 2006 Feb;13(1):1329.

9. Olsen MH, Angell SY, Asma S, Boutouyrie P, Burger D, Chirinos JA et al. A call to action and a lifecourse strategy to address the global burden of raised blood pressure on current and future generations: the Lancet Commission 
on hypertension. Lancet 2016 Nov;388(10060):2665-712. https://doi.org/10.1016/S0140-6736(16)31134-5.

10. Lawes CM, Vander Hoorn S, Rodgers A; International Society of Hypertension. Global burden of blood-pressurerelated disease, 2001. Lancet 2008 May;371(9623):1513-8. https://doi.org/10.1016/S0140-6736(08)60655-8.

11. Hannerz H, Holtermann A. Ischaemic heart disease among workers in occupations associated with heavy lifting. Int J Occup Med Environ Health 2016;29(1):129-36. https://doi. org/10.13075/ijomeh.1896.00472.

12. Work and Health. 2014. Available from: http://www. arbejdsmiljoforskning.dk/da/arbejdsmiljoedata/ arbejdsmiljoe-og-helbred-20/rapporten--danskernesarbejdsmiljoe-2014.

13. Korshøj M, Hannerz H, Marott JL, Schnohr P, Prescott EI, Clays E et al. The Effect of Occupational Lifting on Hypertension Risk: Protocol for a Project Using Data From the Copenhagen City Heart Study. JMIR Res Protoc 2018 Apr;7(4):e93. https://doi.org/10.2196/resprot.9692.

14. Mancia G, Fagard R, Narkiewicz K, Redon J, Zanchetti A, Böhm M et al.; Task Force for the Management of Arterial Hypertension of the European Society of Hypertension and the European Society of Cardiology. 2013 ESH/ ESC Practice Guidelines for the Management of Arterial Hypertension. Blood Press 2014 Feb;23(1):3-16. https://doi. org/10.3109/08037051.2014.868629.

15. Rose GA, Blackburn H. Cardiovascular survey methods. Monogr Ser World Health Organ 1968;56:1-188.

16. Fitzgerald DJ, O'Callaghan WG, O'Malley K, O'Brien ET. Accuracy of the London School of Hygiene and Remler M2000 sphygmomanometers. Clinical science (London, England: 1979). 1981;61 Suppl 7:399s-401s.

17. Doumas M, Papademetriou V, Faselis C, Kokkinos P. Gender differences in hypertension: myths and reality. Curr Hypertens Rep 2013 Aug;15(4):321-30. https://doi. org/10.1007/s11906-013-0359-y.

18. Kronborg CN, Hallas J, Jacobsen IA. Prevalence, awareness, and control of arterial hypertension in Denmark. J Am Soc Hypertens 2009 Jan-Feb;3(1):19-24.e2. https://doi. org/10.1016/j.jash.2008.08.001.

19. Papathanasiou G, Zerva E, Zacharis I, Papandreou M, Papageorgiou E, Tzima C et al. Association of high blood pressure with body mass index, smoking and physical activity in healthy young adults. Open Cardiovasc Med J 2015 Feb;9:5-17. https://doi.org/10.2174/18741924015090 10005.

20. Saladini F, Benetti E, Fania C, Mos L, Casiglia E, Palatini P. Effects of smoking on central blood pressure and pressure amplification in hypertension of the young. Vasc Med 2016 Oct;21(5):422-8. https://doi. org/10.1177/1358863X16647509.

21. Tang KL, Rashid R, Godley J, Ghali WA. Association between subjective social status and cardiovascular disease and cardiovascular risk factors: a systematic review and meta-analysis. BMJ Open 2016 Mar;6(3):e010137. https:// doi.org/10.1136/bmjopen-2015-010137.
22. Prescott E, Holst C, Grønbaek M, Schnohr P, Jensen G, Barefoot J. Vital exhaustion as a risk factor for ischaemic heart disease and all-cause mortality in a community sample. A prospective study of 4084 men and 5479 women in the Copenhagen City Heart Study. Int J Epidemiol 2003 Dec;32(6):990-7. https://doi.org/10.1093/ije/dyg235.

23. Holtermann A, Marott JL, Gyntelberg F, Søgaard K, Mortensen OS, Prescott E et al. Self-reported cardiorespiratory fitness: prediction and classification of risk of cardiovascular disease mortality and longevity--a prospective investigation in the Copenhagen City Heart Study. J Am Heart Assoc 2015 Jan;4(1):e001495. https://doi. org/10.1161/JAHA.114.001495.

24. Lewington S, Clarke R, Qizilbash N, Peto R, Collins R; Prospective Studies Collaboration. Age-specific relevance of usual blood pressure to vascular mortality: a metaanalysis of individual data for one million adults in 61 prospective studies. Lancet 2002 Dec;360(9349):1903-13. https://doi.org/10.1016/S0140-6736(02)11911-8.

25. Leung AA, Nerenberg K, Daskalopoulou SS, McBrien $\mathrm{K}$, Zarnke KB, Dasgupta K et al.; CHEP Guidelines Task Force. Hypertension Canada's 2016 Canadian Hypertension Education Program Guidelines for Blood Pressure Measurement, Diagnosis, Assessment of Risk, Prevention, and Treatment of Hypertension. Can J Cardiol 2016 May;32(5):569-88. https://doi.org/10.1016/j. cjca.2016.02.066.

26. Whelton PK, Carey RM, Aronow WS, Casey DE Jr, Collins KJ, Dennison HC et al. ACC/AHA/AAPA/ABC/ACPM/ AGS/APhA/ASH/ASPC/NMA/PCNA Guideline for the Prevention, Detection, Evaluation, and Management of High Blood Pressure in Adults: A Report of the American College of Cardiology/American Heart Association Task Force on Clinical Practice Guidelines. Hypertension. 2018;71:e13-e115.

27. Klabunde R. Cardiovascular physiology concepts: Lippincott Williams \& Wilkins; 2011.

28. Williams MA, Haskell WL, Ades PA, Amsterdam EA, Bittner V, Franklin BA et al.; American Heart Association Council on Clinical Cardiology; American Heart Association Council on Nutrition, Physical Activity, and Metabolism. Resistance exercise in individuals with and without cardiovascular disease: 2007 update: a scientific statement from the American Heart Association Council on Clinical Cardiology and Council on Nutrition, Physical Activity, and Metabolism. Circulation 2007 Jul;116(5):572-84. https:// doi.org/10.1161/CIRCULATIONAHA.107.185214.

29. Cornelissen VA, Fagard RH, Coeckelberghs E, Vanhees L. Impact of resistance training on blood pressure and other cardiovascular risk factors: a meta-analysis of randomized, controlled trials. Hypertension 2011 Nov;58(5):950-8. https:// doi.org/10.1161/HYPERTENSIONAHA.111.177071.

30. Krause N, Brand RJ, Kaplan GA, Kauhanen J, Malla $\mathrm{S}$, Tuomainen TP et al. Occupational physical activity, energy expenditure and 11-year progression of carotid atherosclerosis. Scand J Work Environ Health 2007 Dec;33(6):405-24. https://doi.org/10.5271/sjweh.1171.

31. Holtermann A, Krause N, van der Beek AJ, Straker L. The 
physical activity paradox: six reasons why occupational physical activity (OPA) does not confer the cardiovascular health benefits that leisure time physical activity does. Br J Sports Med 2018 Feb;52(3):149-50. https://doi.org/10.1136/ bjsports-2017-097965.

32. Hannerz H, Holtermann A. Heavy lifting at work and risk of ischemic heart disease: protocol for a registerbased prospective cohort study. JMIR Res Protoc 2014 Aug;3(3):e45. https://doi.org/10.2196/resprot.3270.

33. Li CY, Sung FC. A review of the healthy worker effect in occupational epidemiology. Occup Med (Lond) 1999 May;49(4):225-9. https://doi.org/10.1093/occmed/49.4.225.

34. Robinson BF. Relation of heart rate and systolic blood pressure to the onset of pain in angina pectoris. Circulation 1967 Jun;35(6):1073-83. https://doi.org/10.1161/01. CIR.35.6.1073.

35. Sukhova GK, Schönbeck U, Rabkin E, Schoen FJ, Poole AR, Billinghurst RC et al. Evidence for increased collagenolysis by interstitial collagenases- 1 and -3 in vulnerable human atheromatous plaques. Circulation 1999 May;99(19):25039. https://doi.org/10.1161/01.CIR.99.19.2503.

36. McArdle WD, Katch FI, Katch VL. Exercise Physiology Energy, Nutrition and Human Performance: Lippincott, Williams and Wilkins; 2007.
37. Wen W, Luo R, Tang X, Tang L, Huang HX, Wen X et al. Age-related progression of arterial stiffness and its elevated positive association with blood pressure in healthy people. Atherosclerosis 2015 Jan;238(1):147-52. https://doi. org/10.1016/j.atherosclerosis.2014.10.089.

38. Fransson E, Knutsson A, Westerholm P, Alfredsson L. Indications of recall bias found in a retrospective study of physical activity and myocardial infarction. J Clin Epidemiol 2008 Aug;61(8):840-7. https://doi.org/10.1016/j. jclinepi.2007.09.004.

39. Stock SR, Fernandes R, Delisle A, Vézina N. Reproducibility and validity of workers' self-reports of physical work demands. Scand J Work Environ Health 2005 Dec;31(6):409_ 37. https://doi.org/10.5271/sjweh.947.

40. Hansen TW, Thijs L, Li Y, Boggia J, Kikuya M, BjörklundBodegård $\mathrm{K}$ et al.; International Database on Ambulatory Blood Pressure in Relation to Cardiovascular Outcomes Investigators. Prognostic value of reading-to-reading blood pressure variability over 24 hours in 8938 subjects from 11 populations. Hypertension 2010 Apr;55(4):1049-57. https:// doi.org/10.1161/HYPERTENSIONAHA.109.140798.

41. Hermida RC, Ayala DE, Fernández JR, Mojón A. Sleeptime blood pressure: prognostic value and relevance as a therapeutic target for cardiovascular risk reduction. Chronobiol Int 2013 Mar;30(1-2):68-86. https://doi.org/10 $.3109 / 07420528.2012 .702581$.

Received for publication: 12 April 2019 